\title{
Sleep complaints in early pregnancy. A cross-sectional study among women attending prenatal care in general practice
}

\author{
Ruth K. Ertmann* (D), Dagny R. Nicolaisdottir, Jakob Kragstrup, Volkert Siersma and Melissa C. Lutterodt
}

\begin{abstract}
Background: Sleep problems in late pregnancy are common, but sleep in early pregnancy is less well described. The aim of this study was to describe the occurrence and severity of sleep complaints in early pregnancy. We asked the women about worries due to sleep problems. Furthermore, we investigated the associations between sleep complaints and pregnancy-related symptoms. This association was studied taking into account physical and mental health, sociodemographic characteristics, and reproductive history of the women.
\end{abstract}

Methods: Cross-sectional study in Danish general practice based on an electronic questionnaire completed by pregnant women and a Pregnancy Health Record filled in by the general practitioner (GP). The questionnaire measured three sleep complaints and 11 common physical pregnancy-related symptoms. The sleep complaints were measured as mild, moderate or severe, and it was recorded how much they worried the women. The associations between the physical pregnancy-related symptoms and sleep complaints were assessed by odds ratios from multivariable logistic regression models.

Results: The questionnaire was completed by 1338 out of 1508 eligible women before the end of gestation week 16. The gestational age ranged from 5 to 16 weeks (median 11 weeks) among the included women. On average, more than one third of the women reported to have at least one of the three sleep complaints in the questionnaire. Problems "taking a long time to fall asleep" was reported by 312 women (23\%), "waking up too early" was reported by 629 (47\%), and 183 (14\%) had been "lying awake most of the night". One sleep complaint was reported by $38 \%$, two by 16 , and $4 \%$ had all three symptoms. The majority were not at all or only mildly worried because of their sleep disturbances, but moderate or severe worries were found among $46 \%$ of those" taking a long time to fall asleep" and among $40 \%$ of those "lying awake most of the night". "Moderate or severe complaints" were reported by 277 (21\%) women "Moderate or severe complaints" were associated with pregnancyrelated physical symptoms, such as back pain, pelvic girdle pain and pelvic cavity pain, but only the association with pelvic cavity pain stayed significant after adjustment for depression.

Conclusion: This study showed that sleep complaints in early pregnancy are common, and sleep complaints showed association with physical as well as mental symptoms. It may be important for pregnant patients that clinicians address depression, and mood in relation to sleep problems during pregnancy.

Keywords: Pregnancy, Sleep, Primary health care, Pregnancy-related symptoms, General practice, Nausea, Back pain, Pelvic girdle pain, Pelvic cavity pain

\footnotetext{
* Correspondence: ruth@sund.ku.dk

Research Unit for General Practice and Section for General Practice, Institute of Public Health, University of Copenhagen, Øster Farimagsgade 5, DK-1014 Copenhagen K, Denmark
}

(c) The Author(s). 2020 Open Access This article is distributed under the terms of the Creative Commons Attribution 4.0 International License (http://creativecommons.org/licenses/by/4.0/), which permits unrestricted use, distribution, and reproduction in any medium, provided you give appropriate credit to the original author(s) and the source, provide a link to the Creative Commons license, and indicate if changes were made. The Creative Commons Public Domain Dedication waiver (http://creativecommons.org/publicdomain/zero/1.0/) applies to the data made available in this article, unless otherwise stated. 


\section{Background}

In many countries, care for pregnant women is shared between general practitioners (GPs), midwives, and obstetric hospital departments. The roles may vary, but often the GP has an important function as coordinator of care, and for many women the GP is the sole provider of health care in the early stage of pregnancy. These early consultations are an opportunity to prepare the woman for the rest of the pregnancy, screen for problems and to discuss her concerns. However, knowledge about the experience of women's health concerns in early pregnancy, such as nausea, vomiting, itching, back pain and sleep complaints is often based on personal clinical experience and relatively small clinical studies.

Sleep disturbances in late pregnancy have been described in several studies [1] and may be explained by profound physiological and anatomical changes such as foetal movements, musculoskeletal discomfort and nycturia [2]. Only a few have studied sleep complaints in early pregnancy, but disturbances may be prevalent [1, 3]. In early pregnancy, sleep complaints may be caused by physical symptoms such as nausea, vomiting or pain. Such physical feelings may be simple explanations for change in sleep patterns, but complaints may have a more complex background that includes hormonal, mechanical, emotional and sociological factors [4-6]. A review studying short sleep duration, poor sleep quality and insomnia during pregnancy found that these conditions related to a number of adverse pregnancy outcomes, such as prenatal depression, gestational diabetes, pre-eclampsia, abnormal length of labour, cesarean delivery, alteration in fetal growth and preterm birth. The mechanisms behind are unclear, but sleep disturbances may produce changes in the hypothalamic-pituitaryadrenal axis and abnormal immune/inflammatory reactions [7]. Further, sleep is critical for glucose metabolism and several meta-analyses found that both self-reported and objectively measured sleep is assoiated with hyperglycemia and an increased risk of gestational diabetes mellitus (GDM) [8-10]. Sleep is also important for blood pressure; both short and long sleep duration as well as poor sleep quality are associated with elevated blood pressure [11], measured with Pittsburgh Sleep Quality Index (PSQI) [12]. Lastly, a systematic review found evidence for the impact of poor sleep on mental health [13]. Up to $85 \%$ of pregnant women want to discuss pregnancy-related symptoms during the preventive health checks performed by their general practitioner (GP) or the midwife [14]. It may, therefore, be important for GPs and midwives to address sleep problems early in pregnancy. To do this, knowledge about sleep problems in pregnant women is needed, and it is important to be aware of any worries sleep problems may produce.
The aim of this study was to describe the occurrence and severity of sleep complaints in early pregnancy ( $\leq$ gestation week 16). We asked the women about worries due to sleep problems. Furthermore, we investigated the associations between sleep complaints and pregnancyrelated symptoms. This association was studied, taking into account the physical and mental health, sociodemographic characteristics, and reproductive history of the women.

\section{Methods \\ Study design}

Cross-sectional study comprising questionnaires and Pregnancy Health Records for pregnant women participating in the first prenatal care visit to their GPs.

\section{Setting}

The healthcare system in Denmark is tax-funded, and care is free of charge for the patient. The majority of Danes (99\%) are registered with a GP who functions as gatekeeper to secondary care. A minimum of three prenatal care visits and one postpartum are offered by the GP. The first consultation is offered at gestational age 6-10 weeks to all women who wish to go through with their pregnancy. This consultation, which precedes other contacts to the healthcare system, is accepted by almost $100 \%$ of women. In this consultation a thorough and structured record is established (the Pregnancy Health Record) and sent to midwives and hospital departments. The second and third prenatal care visits usually take place at pregnancy weeks 25 and 32, and the postpartum examination 8 weeks after birth.

\section{Sampling of the pregnant women}

GPs were recruited from two of the five Danish administrative Regions (The Capital Region of Denmark and Region Zealand) with a total of 1561 practices, organised in 53 geographical units. Among these, 19 units were randomly selected. The 308 practices situated in the selected geographical area were individually contacted and asked to participate in the study. A total of 192 practices agreed to participate. The practices could be either single-handed or partnerships. Among the 190 participating practices, 117 were active in the study and recruited one or more pregnant women to the study. The 117 active practices comprised a total of 294 GPs.

All pregnant women booking an appointment for the first prenatal care visit with one of the participating GPs were eligible for inclusion in the project. The women received oral and written information on the project and were consecutively included after signing a consent form. The inclusion period was from 1 April 2015 to 15 August 2016. Women were excluded if they did not complete the electronic questionnaire (all in Danish), if 
they withdrew consent or if the pregnancy ended in abortion.

\section{Data collection}

Data were collected from the Pregnancy Health Record and from an electronic patient questionnaire. The electronic questionnaire was sent to the women after the first prenatal care visit. The questionnaire could only be returned when it was fully completed. Nonrespondents were sent two reminders and some were contacted by phone.

\section{Pregnancy health record}

The Pregnancy Health Record was filled in by the GP at the first prenatal care visit. The Pregnancy Health Record is a standardised two-page record introduced by the health authorities in Denmark [15]. In this study, the following parts of the record are used: lifestyle habits, reproductive background and previous psychiatric disorders. A copy of the record to be used in the project was received from the GPs.

\section{Questionnaire}

Only questionnaires completed before or in gestational week 16 were used for this study. The questionnaire measured three sleep symptoms: 1) Has it taken you a long time to fall asleep in the past week? (Categorised as: no, mild, moderate, severe). 2) Have you been waking up too early in the past week? (no, mild, moderate, severe). 3) Have you been lying awake most of the night in the past week? (no, mild, moderate, severe). In relation to all three sleep symptoms, the women were further asked whether they had been worried about the symptoms (no, mildly, moderately, severely). The sleep questions used in our study derive from the Nottingham Health Profile (NHP) [16]. Moreover, the questions have been used and showed good reliability and validity in two Danish Breast Cancer studies [17, 18].

Furthermore, the questionnaire asked about a selection of pregnancy-related physical symptoms including nausea, vomiting, back pain, pelvic girdle pain, pelvic cavity pain, vulvar itching, varicose veins, leg cramps, pregnancy itching, vaginal bleeding and uterine contractions; answers were categorised as present or not present. The questionnaire contained anatomical pictures with arrows pointing at e.g. point of pelvic girdle pain.

Other information obtained from the questionnaire and the Pregnancy Health Record was used to adjust for confounding and arranged in three blocks: Block I sociodemographics: marital status (married, cohabiting, single), children living at home (no, yes), education (primary, secondary and higher education), occupation (employed, student, other, unemployed, sick leave), income of household (<39,999 EUR, 40000-79,999 EUR,
80000-119,999 EUR, $\geq 120,000$ EUR, do not want to answer) and age (5-years grouping). Lifestyle habits: smoking during pregnancy (no, yes), drinking alcohol during pregnancy (no, yes) and use of drugs (no, yes).

Block II - physical health: self-assessed health (very good, good, fair, poor, very poor), self-assessed fitness (very good, good, fair, poor, very poor). The block with health-related data also included information from the Pregnancy Health Record concerning reproductive background: parity $(0,1,>1)$, previous abortions $(0,1,>1)$, in vitro fertilisation (no, yes) and week of gestation.

Block III - mental health: previous psychological difficulties (no, yes - but no health care, yes - with health care), known psychiatric disease (no, yes), and symptoms of depression and anxiety. Depression was measured with the Major Depression Inventory, (MDI) [19]. The MDI contains 10 items measured on a 6-point scale from 0 (never) to 5 (all the time) with in a time frame of the past 2 weeks. The total score of the MDI has a theoretical range from 0 (no depression) to 50 (extreme depression). A total score of 21 or more is indicative of a mild depressive episode according to ICD-10 [19]. Cronbach's alpha of the MDI is 0.89 [20]. Anxiety was measured with the Anxiety Symptom Scale (ASS), which is constructed analogue to the MDI, covering 10 items for measuring the states of anxiety [19]. The total ASS score has a theoretical range from 0 (no anxiety) to 50 (extreme anxiety).

\section{Statistical analyses}

Characteristics of the study population were compared between women without sleep complaints and those with sleep complaints. Multivariable logistic regression analysis was used to test the associations between "moderate or severe sleep complaints" and pregnancy-related physical symptoms. Women were labelled as having "moderate or severe sleep problems", if they had reported a moderate or severe problem in response to one or more of the three sleep questions. The associations were assessed in five ways: unadjusted, adjusted for each of the three blocks individually, and adjusted for all three blocks simultaneously. The purpose of these adjustments was to see whether the additional information could explain the associations apparent in the unadjusted assessment. Only women with complete records and questionnaires were included in the regression analysis.

A $p$-value $<0.001$ was considered statistically significant. We have specifically lowered the level of significance from the usual 0.05 to 0.001 to minimise the risk of finding spurious associations because of multiple testing. The statistical analyses were performed with SAS version 9.4 (SAS Institute, Cary, NC, USA). 


\section{Results}

A total of 1508 pregnant women gave informed consent to participate in the study. We received completed questionnaires from 1455 (96\%), Pregnancy Health Records for 1479 women (98\%), and both datasets were received for 1442 women (96\%). Women who answered the first questionnaire after week 16 were excluded, leaving 1338 women for the analysis. The gestational age of the women at the time of completing the questionnaire was between 5 and 16 weeks (range) and the median was week 11 .

The demographic characteristics and health of participating women are described in Table 1.

Women with sleep complaints had worse self-rated health and worse self-rated fitness. Furthermore, they had experiences of previous psychological difficulties, higher depression and anxiety scores.

On average, more than one third of the pregnant women reported to have at least one of the three sleep complaints in the questionnaire. A single sleep complaint was reported by 509 (38\%), two by $219(16 \%)$, and 59 (4\%) had all three complaints. Three hundred and twelve women $(23 \%)$ had to some degree "taking a long time to fall asleep", 629 (47\%) had been "waking up too early" and 183 (14\%) had been "lying awake most of the night" (Table 2). The majority were not or only mildly worried because of their sleep disturbances, but moderate or severe worries were found among $46 \%$ of those "taking a long time to fall asleep" and among $40 \%$ of those "lying awake most of the night" (Table 2).

"Moderate or severe sleep complaints" were reported by 277 women $(21 \%)$. These women were younger, had shorter education, lower household income, lower selfrated health, lower self-rated fitness, and they had more psychological and psychiatric problems (Table 1).

The primary unadjusted analysis showed statistically significant $(P<0.001)$ associations between "moderate or severe sleep complaints" and the following pregnancyrelated physical symptoms: back pain, pelvic girdle pain, pelvic cavity pain (Table 3). No significant associations with sleep complaints were found for nausea, vomiting, vaginal bleeding, itching, varicose veins, or uterine contractions. Table 3 shows the results of the logistic regression analyses, which is adjusted for other characteristics of the 1338 women. The associations between pregnancy-related symptoms and sleep complaints all remained statistically significant, when age and sociodemographic characteristics of the woman were included in the analysis (Block I) and when reproductive background and current pregnancy were included in the analysis (Block III). However, when adjusted for physical and mental health (Block II), none of the associations remained statistically significant. We analysed the reason for this weakening of the associations by adjusting these associations for the variables that were related to sleep complaints as well as to the pregnancy-related symptoms in Block II individually: previous psychological difficulties, depression score, anxiety score, and self-assessed fitness. Depression score appeared to explain the weakening of the associations to the greatest extent.

\section{Discussion}

\section{Statement of principal findings}

On average, more than one third of pregnant women experienced some degree of poor sleep in early pregnancy, although most symptoms were rated as minor. Waking up too early was reported by $47 \%$ of the women, but few were worried. On the other hand, $46 \%$ of the women who had been "taking a long time to fall asleep", and $40 \%$ of the women who had been "lying awake most of the night" were worried to a moderate or severe degree. Sleep complaints showed association with other pregnancy-related symptoms, such as back pain, pelvic girdle pain and pelvic cavity pain, but only the association with pelvic cavity pain stayed significant after adjustment for depression.

\section{Limitations of the study}

No exclusion criteria were used, but with regard to representativity for the general population of women in early pregnancy a number of factors must be considered. The questionnaire was in Danish and results may be less representative for non-native women. The GPs participating in the study were sampled by a systematic procedure based on random selection from two representative regions of Denmark, including urban and rural areas, and areas with low as well as high social status. This strengthens the geographical representation of the study, but the GP practices that voluntarily chose to contribute constitute only approximately $40 \%$ of those asked. There were very few nonrespondents among women who accepted to participate, and complete data were obtained from almost all participants. However, not all eligible women may have been asked, and not all women managed to have had their first prenatal care visit between pregnancy weeks $6-10$, where the inclusion was supposed to take place. This delay in receiving the signed consent form with the women's e-mail from the GPs led to a delay in answering among the participating women. Those women were asked to recall how they experienced symptoms and feelings around week 9-10.

We assessed sleep complaints by means of questions to the pregnant women. Such subjective measures of sleep duration and sleep efficiency have previously been shown to be correlated with objective measures [10, 21], but may obviously be affected by the individual's reporting style. The degree of trouble and the level of worries can, however, only be assessed by the women 
Table 1 Participant demographics

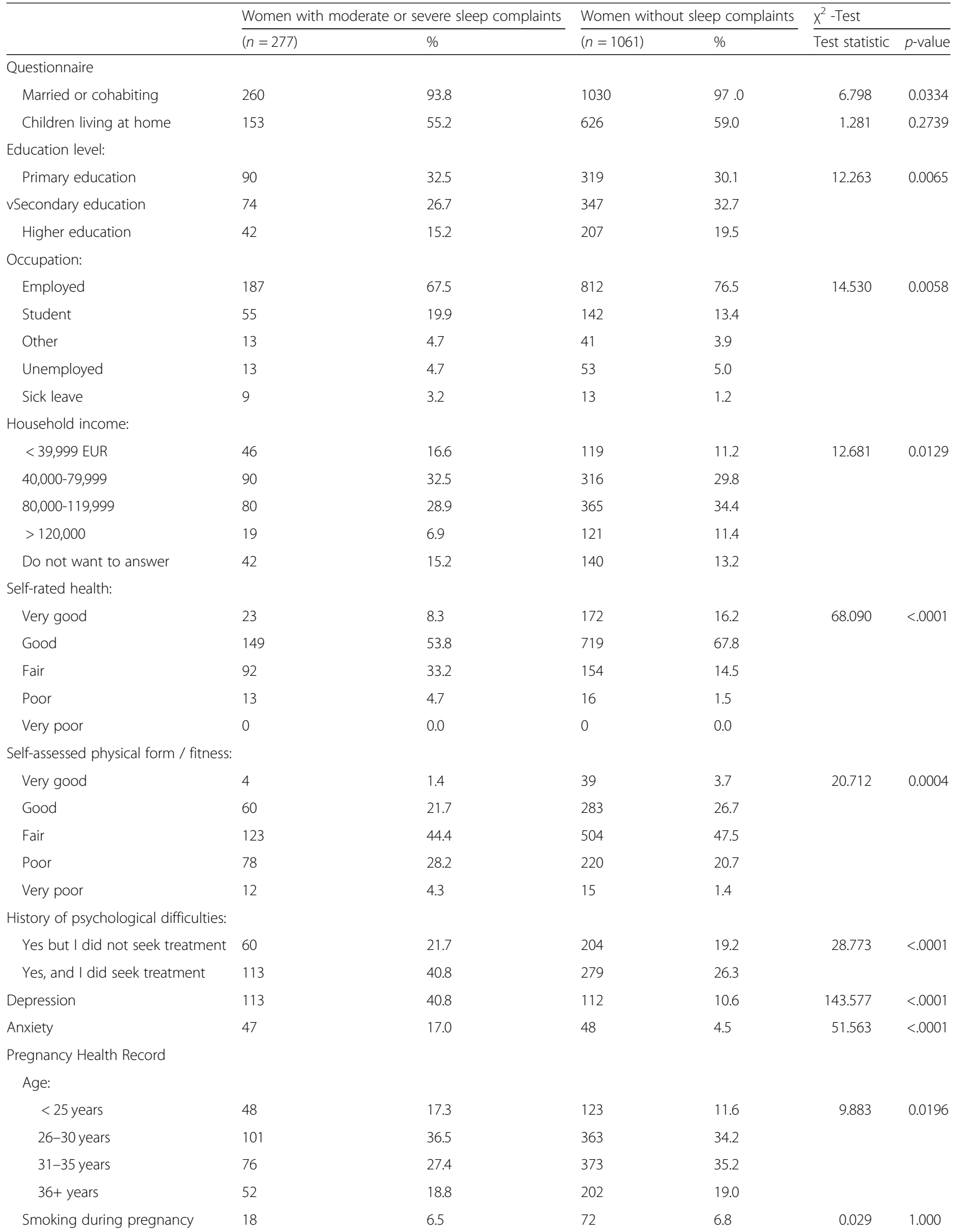


Table 1 Participant demographics (Continued)

\begin{tabular}{|c|c|c|c|c|c|c|}
\hline & \multicolumn{2}{|c|}{ Women with moderate or severe sleep complaints } & \multicolumn{2}{|c|}{ Women without sleep complaints } & \multicolumn{2}{|l|}{$x^{2}$-Test } \\
\hline & $(n=277)$ & $\%$ & $(n=1061)$ & $\%$ & Test statistic & $p$-value \\
\hline Alcohol during pregnancy & 2 & 0.7 & 7 & 0.7 & 0.013 & 1.000 \\
\hline Use of recreational drugs & 1 & 0.4 & 2 & 0.2 & 0.292 & 0.5017 \\
\hline Psychiatric disease & 32 & 11.6 & 65 & 6.1 & 9.618 & 0.0038 \\
\hline Fertility treatment & 35 & 12.6 & 95 & 9.0 & 3.394 & 0.0689 \\
\hline \multicolumn{7}{|l|}{ Abortion: } \\
\hline Miscarriage, one spontaneous & 43 & 19.5 & 125 & 11.8 & 6.570 & 0.1604 \\
\hline Miscarriage, several times & 23 & 8.3 & 78 & 7.4 & & \\
\hline Induced abortion & 53 & 19,2 & 171 & 16.1 & & \\
\hline \multicolumn{7}{|l|}{ Given birth: } \\
\hline Yes, once & 102 & 36.8 & 390 & 36.8 & 2.080 & 0.3535 \\
\hline Yes, several times & 41 & 14.8 & 194 & 18.3 & & \\
\hline \multicolumn{7}{|l|}{ Gestation age, weeks: } \\
\hline 5-10 weeks & 109 & 40.4 & 435 & 42.1 & 0.2790 & 0.5974 \\
\hline $11-16$ weeks & 161 & 59.6 & 597 & 57.9 & & \\
\hline
\end{tabular}

Characteristics of all 1338 participating women and the 277 women with significant sleep problems (one or more" moderate or severe sleep complaints") Footnote: We have missing gestation age data from 36 women. 29 of these women did not have a sleep problem and 7 women did have one. These were included in the analysis because with a high likelihood they have a gestation age less than 17 weeks

themselves. Unfortunately, we do not have preconception information about sleep complaints and, therefore, cannot be sure that problems are different post-conception. Significantly more mid-sleep awakenings have, however, previously been found in pregnant women compared to non-pregnant women [22].

The most commonly used postpartum instrument is the Edinburgh Postnatal Depression Scale (EPDS), which was developed to measure postpartum depression. For our study we used the MDI because it is more often used in clinical practice by GPs in Denmark. MDI has been demonstrated to have good validity and reliability, and only includes is a single question about sleep [23]. Cronbach's Alpha value for the MDI in our study was 0.84 and for the ASS was 0.80. Factors associated with sleep problems were measured with validated scales when possible (e.g. sociodemographic status (https:// www.dst.dk/da/).

Table 2 Sleep questions

\begin{tabular}{|c|c|c|c|c|c|c|c|c|c|c|}
\hline & \multicolumn{2}{|c|}{$\begin{array}{l}\text { Does not have } \\
\text { the sleep } \\
\text { problem }\end{array}$} & \multicolumn{8}{|c|}{ Does have the sleep problems } \\
\hline & \multirow[b]{2}{*}{$\mathrm{n}$} & \multirow[b]{2}{*}{$(\%)$} & \multicolumn{2}{|c|}{$\begin{array}{l}\text { No } \\
\text { complaints }\end{array}$} & \multicolumn{2}{|c|}{$\begin{array}{l}\text { Mild } \\
\text { complaints }\end{array}$} & \multicolumn{2}{|c|}{$\begin{array}{l}\text { Moderate } \\
\text { complaints }\end{array}$} & \multicolumn{2}{|c|}{$\begin{array}{l}\text { Severe } \\
\text { complaints }\end{array}$} \\
\hline & & & $\bar{n}$ & $(\%)$ & $\bar{n}$ & $(\%)$ & $\bar{n}$ & $(\%)$ & $\bar{n}$ & $\overline{(\%)}$ \\
\hline \multicolumn{11}{|l|}{ "Fall asleep" } \\
\hline Has it taken you a long time to fall asleep in the past week? & $1026 / 1338$ & $77 \%$ & $30 / 312$ & $9 \%$ & $171 / 312$ & $55 \%$ & $68 / 312$ & $22 \%$ & $43 / 312$ & $14 \%$ \\
\hline Have you been worried* about taking along time to fall asleep? & & & $0 / 30$ & $0 \%$ & $1 / 171$ & $1 \%$ & $11 / 68$ & $16 \%$ & $13 / 43$ & $30 \%$ \\
\hline \multicolumn{11}{|l|}{ "Waking up too early" } \\
\hline Have you been waking up too early in the past week? & $709 / 1338$ & $53 \%$ & $124 / 629$ & $20 \%$ & $334 / 629$ & $53 \%$ & $116 / 629$ & $18 \%$ & $55 / 629$ & $9 \%$ \\
\hline Have you been worried* about waking up too early? & & & $0 / 124$ & $0 \%$ & $1 / 334$ & $0 \%$ & $16 / 116$ & $14 \%$ & $5 / 55$ & $9 \%$ \\
\hline \multicolumn{11}{|l|}{ "Lying awake most of the night" } \\
\hline Have you been lying awake most of the night in the past week? & $1155 / 1338$ & $86 \%$ & $5 / 183$ & $3 \%$ & $58 / 183$ & $32 \%$ & $55 / 183$ & $30 \%$ & $65 / 183$ & $35 \%$ \\
\hline Have you been worried* about lying awake most of the night? & & & $0 / 5$ & $0 \%$ & $1 / 58$ & $2 \%$ & $8 / 55$ & $15 \%$ & $16 / 65$ & $25 \%$ \\
\hline
\end{tabular}


Table 3 The associations between "moderate or severe sleep complaints", other pregnancy-related symptoms and other characteristics of the pregnant women

\begin{tabular}{|c|c|c|c|c|c|c|c|}
\hline & $\mathrm{N}(\%)$ & $\begin{array}{l}\mathrm{N}(\%) \text { with } \\
\text { significant sleep } \\
\text { complaints }\end{array}$ & Unadjusted & $\begin{array}{l}\text { Block I: Adjusted for age } \\
\text { and sociodemographic } \\
\text { characteristics }\end{array}$ & $\begin{array}{l}\text { Block II: Adjusted for physical } \\
\text { and mental health status and } \\
\text { resources }\end{array}$ & $\begin{array}{l}\text { Block III: Adjusted } \\
\text { for reproductive } \\
\text { background }\end{array}$ & $\begin{array}{l}\text { Adjusted } \\
\text { for all } \\
\text { blocks }\end{array}$ \\
\hline Variable & & & $\begin{array}{l}\text { OR } \\
{[95 \% \mathrm{Cl}]}\end{array}$ & OR $[95 \% \mathrm{Cl}]$ & OR $[95 \% \mathrm{Cl}]$ & OR $[95 \% \mathrm{Cl}]$ & $\begin{array}{l}\text { OR } \\
{[95 \% \mathrm{Cl}]}\end{array}$ \\
\hline Nausea & $\begin{array}{l}1182 \\
(88.34 \%)\end{array}$ & $259(93.50 \%)$ & $\begin{array}{l}2.15[1.29- \\
3.58]\end{array}$ & $2.07[1.23-3.49]$ & $1.57[0.92-2.69]$ & 2.19 [1.31-3.65] & $\begin{array}{l}1.56 \\
{[0.90-} \\
2.72]\end{array}$ \\
\hline $\begin{array}{l}\text { Pelvic cavity } \\
\text { pain }\end{array}$ & $\begin{array}{l}755 \\
(56.43 \%)\end{array}$ & $189(68.23 \%)$ & $\begin{array}{l}1.88[1.42- \\
2.49]^{*}\end{array}$ & $1.82[1.36-2.43]^{*}$ & $1.65[1.22-2.24]$ & $1.87[1.41-2.50]^{*}$ & $\begin{array}{l}1.61 \\
{[1.17-} \\
2.21]\end{array}$ \\
\hline Vomiting & $\begin{array}{l}527 \\
(39.39 \%)\end{array}$ & $117(42.24 \%)$ & $\begin{array}{l}1.16[0.89- \\
1.52]\end{array}$ & 1.10 [0.83-1.45] & $0.89[0.66-1.20]$ & 1.14 [0.87-1.49] & $\begin{array}{l}0.83 \\
{[0.61-} \\
1.14]\end{array}$ \\
\hline Back pain & $\begin{array}{l}483 \\
(36.10 \%)\end{array}$ & $132(47.65 \%)$ & $\begin{array}{l}1.84[1.41- \\
2.41]^{*}\end{array}$ & $1.75[1.32-2.31]^{*}$ & 1.39 [1.03-1.87] & $1.83[1.39-2.39]^{*}$ & $\begin{array}{l}1.36 \\
{[1.00-} \\
1.84]\end{array}$ \\
\hline $\begin{array}{l}\text { Pelvic girdle } \\
\text { pain }\end{array}$ & $\begin{array}{l}438 \\
(32.74 \%)\end{array}$ & $119(42.96 \%)$ & $\begin{array}{l}1.75[1.34- \\
2.30]^{*}\end{array}$ & $1.69[1.28-2.24]^{*}$ & $1.42[1.06-1.92]$ & $1.75[1.33-2.30]^{*}$ & $\begin{array}{l}1.41 \\
{[1.03-} \\
1.92]\end{array}$ \\
\hline $\begin{array}{l}\text { Vulvar } \\
\text { itching }\end{array}$ & $\begin{array}{l}240 \\
(17.94 \%)\end{array}$ & $56(20.22 \%)$ & $\begin{array}{l}1.21[0.87- \\
1.69]\end{array}$ & 1.18 [0.84-1.66] & $1.02[0.70-1.47]$ & $1.23[0.88-1.72]$ & $\begin{array}{l}1.02 \\
{[0.70-} \\
1.49]\end{array}$ \\
\hline $\begin{array}{l}\text { Vaginal } \\
\text { bleeding }\end{array}$ & $\begin{array}{l}230 \\
(17.19 \%)\end{array}$ & $60(21.66 \%)$ & $\begin{array}{l}1.45[1.04- \\
2.01]\end{array}$ & $1.44[1.03-2.02]$ & $1.44[1.01-2.07]$ & 1.45 [1.04-2.02] & $\begin{array}{l}1.43 \\
{[0.99-} \\
2.08]\end{array}$ \\
\hline $\begin{array}{l}\text { Pregnancy } \\
\text { itching }\end{array}$ & $\begin{array}{l}210 \\
(15.70 \%)\end{array}$ & 44 (15.88\%) & $\begin{array}{l}1.02[0.71- \\
1.46]\end{array}$ & $0.92[0.63-1.33]$ & $0.91[0.61-1.35]$ & 1.00 [0.69-1.44] & $\begin{array}{l}0.82 \\
{[0.55-} \\
1.24]\end{array}$ \\
\hline Leg cramp & $\begin{array}{l}112 \\
(8.37 \%)\end{array}$ & $34(12.27 \%)$ & $\begin{array}{l}1.76[1.15- \\
2.70]\end{array}$ & 1.63 [1.04-2.55] & $1.36[0.84-2.18]$ & $1.77[1.15-2.72]$ & $\begin{array}{l}1.32 \\
{[0.80-} \\
2.17]\end{array}$ \\
\hline $\begin{array}{l}\text { Uterine } \\
\text { contractions }\end{array}$ & $\begin{array}{l}41 \\
(3.06 \%)\end{array}$ & $11(3.97 \%)$ & $\begin{array}{l}1.42[0.70- \\
2.87]\end{array}$ & $1.60[0.77-3.32]$ & $1.42[0.65-3.10]$ & 1.55 [0.76-3.20] & $\begin{array}{l}1.68 \\
{[0.74-} \\
3.80]\end{array}$ \\
\hline $\begin{array}{l}\text { Varicose } \\
\text { veins }\end{array}$ & $\begin{array}{l}31 \\
(2.32 \%)\end{array}$ & 7 (2.53\%) & $\begin{array}{l}1.12[0.48- \\
2.63]\end{array}$ & 1.30 [0.54-3.09] & $0.92[0.36-2.35]$ & 1.26 [0.53-2.99] & $\begin{array}{l}1.15 \\
{[0.43-} \\
3.05]\end{array}$ \\
\hline
\end{tabular}

The associations between sleep complaints and a number of other pregnancy-related symptoms among the 277 women who reported one or more "moderate or severe sleep complants". For each pregnancy-related symptom the results of five logistic regression analyses are reported: unadjusted, adjusted separately for age and sociodemographic characteristics (Block I), adjusted for physical and mental health status and resources (Block II), adjusted for reproductive background (Block III), and adjusted for all three blocks simultaneously. Associations with a p-value $<0.001$ were considered statistically significant and marked with *

\section{Findings in context of existing research}

Problems with sleep in late pregnancy have been described in many studies and may affect more than $2 / 3$ of women $[24,25]$. The enlarged uterus and movements of the child may, for example, explain this. Studies from early pregnancy are fewer and the population size of our study is relatively large. We found poor sleep quality among $47 \%$ of the women. This is lower compared to $74 \%$ poor sleepers among 346 self-selected women in the first trimester in a recent web-based study [26], and other small cross-sectional studies have found frequencies between 28 and 38\% [27] and 60\% [28]. Sleep complaints in the non-pregnant populations seem to be less frequent than among first trimester pregnant women. A national sleep survey of Australian adults reported that 33-45\% had inadequate sleep [29], and a Japanese study found the frequencies to be around 29\% [30].

We found associations between sleep complaints and some pregnancy-related physical symptoms, leading us to explore possible mechanisms through which sleep in pregnancy may impact health or vice versa. A study exploring mid-sleep awakenings found no associations with nausea and indigestion [22]. Similarly, we found no association with nausea. Another study found that women experiencing distressing physical symptoms during pregnancy more often suffer from poorer sleep quality and more symptoms of depression [31], which corresponds well with our result showing association with sleep 
complaints and mood. Furthermore, our women had higher depression score (MDI score > 20) 8 weeks postpartum, if they experienced physical discomfort in early pregnancy, such as back pain and pelvic cavity pain [32]. Pain as well as depression affect sleep, and depression may interact with pregnant women's subjective impression of pregnancy-related pain and their sleep experiences. This could be described as maternal stress, inasmuch as several studies have found that sleep problems relate to maternal stress. These heterogeneity studies show associations with elevated blood pressure [11], childhood abuse [33], intimate partner violence [34] and higher levels of symptoms of anxiety and depression, both during pregnancy and postpartum [13, 35]. However, it is debatable how strong this relation is, as it seems that our women were not so distressed that the sleep complaint worried them. Nevertheless, some of the pregnant women may have been worried, because those who experienced poor sleep quality had a high use of health care [36]. Overall, GPs have a unique opportunity for reducing maternal distress by introducing sleep intervention, which represents a potential low-cost, nonpharmacological prevention and treatment strategy for postpartum mental illness, by articulating that the pregnant women should be aware of the connection between sleep and symptoms of depression and anxiety [13, 37, 38]. In addition, the women should be encouraged to engage in physical activity and exercise during pregnancy, as studies have shown that this has an overall beneficial effect on sleep characteristics and sleep continuity and on the woman's mental state $[39,40]$.

\section{Conclusion}

This study showed that sleep complaints in early pregnancy are common, and that they did not seem to worry the women a great deal. Sleep complaints also showed association with physical as well as mental symptoms.

\section{Implications of the findings}

Sleep complaints in early pregnancy are common and should be addressed by the GP and midwife at the first prenatal care visit. Anxiety and mood may be related and relevant topics for discussion in relation to sleep problems.

\section{Supplementary information}

Supplementary information accompanies this paper at https://doi.org/10. 1186/s12884-020-2813-6.

\section{Additional file 1. Questionnaire.}

\section{Abbreviations}

Ass: Anxiety Symptom Scale; GPs: General practitioners; MDI: Major Depression Inventory

\section{Acknowledgements}

The views expressed in this article are those of the authors and not necessarily those of the foundations.

\section{Authors' contributions}

RE designed the study. RE and DN collected the data, and RE, DN and VS analysed the data. RE, JK and MCL drafted the paper. All authors have read, discussed and approved the manuscript.

\section{Funding}

Novo Nordisk Foundation, Region Zealand, Danish Research Foundation of General Practice, A.P. Moller Foundation, Lilly and Herbet Hansen's

Foundation and Jacob and Orla Madsen's Foundation. We declare that the foundations had no input on the study design, collection, analysis, and interpretation of data and on writing the manuscript.

\section{Availability of data and materials}

The datasets used and/or analysed during the present study are available from the corresponding author on request.

\section{Ethics approval and consent to participate}

The practice staff gave oral and written information about the project to eligible women. All patients deciding to participate signed a consent form, giving access to the data from their Pregnancy Health Record and allowing the researchers to contact them and send the questionnaire by email. All procedures were in accordance with the Helsinki II Declaration and Danish law. Approval from the Danish Data Protection Agency was obtained (Journal 2014-41-3018). According to Danish law, studies based entirely on data collected from registers and questionnaires do not need approval from an ethics committee.

\section{Consent for publication}

Not applicable.

\section{Competing interests}

The authors declare that no competing interests exist.

Received: 25 October 2018 Accepted: 13 February 2020

Published online: 22 February 2020

\section{References}

1. Wilson DL, Barnes M, Ellett L, Permezel M, Jackson M, Crowe SF. Decreased sleep efficiency, increased wake after sleep onset and increased cortical arousals in late pregnancy. Aust N Z J Obstet Gynaecol. 2011;51(1):38-46.

2. Hutchison BL, Stone PR, McCowan LM, Stewart AW, Thompson JM, Mitchell EA. A postal survey of maternal sleep in late pregnancy. BMC Pregnancy Childbirth. 2012:12:144.

3. Lee KA, Zaffke ME, McEnany G. Parity and sleep patterns during and after pregnancy. Obstet Gynecol. 2000;95(1):14-8.

4. Dzaja A, Arber S, Hislop J, Kerkhofs M, Kopp C, Pollmacher T, Polo-Kantola P, Skene DJ, Stenuit P, Tobler I, et al. Women's sleep in health and disease. J Psychiatr Res. 2005;39(1):55-76.

5. Parry BL, Martinez LF, Maurer EL, Lopez AM, Sorenson D, Meliska CJ. Sleep, rhythms and women's mood. Part I. menstrual cycle, pregnancy and postpartum. Sleep Med Rev. 2006;10(2):129-44.

6. Oyiengo D, Louis M, Hott B, Bourjeily G. Sleep disorders in pregnancy. Clin Chest Med. 2014;35(3):571-87.

7. Palagini L, Gemignani A, Banti S, Manconi M, Mauri M, Riemann D. Chronic sleep loss during pregnancy as a determinant of stress: impact on pregnancy outcome. Sleep Med. 2014;15(8):853-9.

8. Reutrakul S, Anothaisintawee T, Herring SJ, Balserak BI, Marc I, Thakkinstian A. Short sleep duration and hyperglycemia in pregnancy: aggregate and individual patient data meta-analysis. Sleep Med Rev. 2018;40:31-42.

9. Xu YH, Shi L, Bao YP, Chen SJ, Shi J, Zhang RL, Lu L. Association between sleep duration during pregnancy and gestational diabetes mellitus: a metaanalysis. Sleep Med. 2018;52:67-74.

10. Facco FL, Parker CB, Hunter S, Reid KJ, Zee PC, Silver RM, Haas DM, Chung $J$ H, Pien GW, Nhan-Chang CL, et al. Association of Adverse Pregnancy Outcomes with Self-Reported Measures of sleep duration and timing in women who are nulliparous. J Clin Sleep Med. 2018;14(12):2047-56. 
11. Williams MA, Miller RS, Qiu C, Cripe SM, Gelaye B, Enquobahrie D. Associations of early pregnancy sleep duration with trimester-specific blood pressures and hypertensive disorders in pregnancy. Sleep. 2010; 33(10):1363-71.

12. Okada K, Saito I, Katada C, Tsujino T. Influence of quality of sleep in the first trimester on blood pressure in the third trimester in primipara women. Blood Press. 2019;28:1-11.

13. Lawson A, Murphy KE, Sloan E, Uleryk E, Dalfen A. The relationship between sleep and postpartum mental disorders: a systematic review. J Affect Disord. 2015;176:65-77.

14. Lindenskov L, Kristensen FB, Andersen AM, Andersen KV, Hermann N, Knudsen WW, Nielsen HK. Preventive check-ups of pregnant women in Denmark. Common ailments in pregnancy. Ugeskr Laeger. 1994;156(19): 2897-901.

15. The Danish Health Board. https://sundhedsstyrelsen.dk/da/sundhed/ / media/D76304BDB11F48BBB1E83CBC8E0AD85B.ashx

16. Hunt SM, McEwen J, McKenna SP. Measuring health status: a new tool for clinicians and epidemiologists. J Royal College General Practitioners. 1985; 35(273):185-8.

17. Brodersen J, Thorsen H, Kreiner S. Validation of a condition-specific measure for women having an abnormal screening mammography. Value Health. 2007;10(4):294-304.

18. Brodersen J, Thorsen $\mathrm{H}$. Consequences of screening in breast Cancer (COSBC): development of a questionnaire. Scand J Prim Health Care. 2008;26(4): 251-6.

19. Bech P. Clinical psychometrics. Oxford: Wiley-Blackwell; 2012.

20. Nielsen MG, Ornbol E, Vestergaard M, Bech P, Christensen KS. The construct validity of the major depression inventory: a Rasch analysis of a self-rating scale in primary care. J Psychosom Res. 2017;97:70-81.

21. Croy I, Smith MG, Gidlof-Gunnarsson A, Persson-Waye K. Optimal questions for sleep in epidemiological studies: comparisons of subjective and objective measures in laboratory and field studies. Behav Sleep Med. 2017 15(6):466-82.

22. Baratte-Beebe KR, Lee K. Sources of midsleep awakenings in childbearing women. Clin Nurs Res. 1999;8(4):386-97.

23. Bech P, Timmerby N, Martiny K, Lunde M, Soendergaard S. Psychometric evaluation of the major depression inventory (MDI) as depression severity scale using the LEAD (longitudinal expert assessment of all data) as index of validity. BMC Psychiatry. 2015;15:190.

24. Sivertsen B, Hysing M, Dorheim SK, Eberhard-Gran M. Trajectories of maternal sleep problems before and after childbirth: a longitudinal population-based study. BMC Pregnancy Childbirth. 2015;15:129.

25. Ko SH, Chang SC, Chen CH. A comparative study of sleep quality between pregnant and nonpregnant Taiwanese women. J Nursing Scholarship. 2010; 42(1):23-30.

26. Mindell JA, Cook RA, Nikolovski J. Sleep patterns and sleep disturbances across pregnancy. Sleep Med. 2015;16(4):483-8.

27. Okun ML, Kline CE, Roberts JM, Wettlaufer B, Glover K, Hall M. Prevalence of sleep deficiency in early gestation and its associations with stress and depressive symptoms. J Womens Health (2002). 2013;22(12):1028-37.

28. Hung HM, Tsai PS, Ko SH, Chen $\mathrm{CH}$. Patterns and predictors of sleep quality in Taiwanese pregnant women. MCN Am J Matern Child Nurs. 2013;38(2): 95-101.

29. Adams RJ, Appleton SL, Taylor AW, Gill TK, Lang C, McEvoy RD, Antic NA. Sleep health of Australian adults in 2016: results of the 2016 sleep Health Foundation national survey. Sleep Health. 2017;3(1):35-42.

30. Liu X, Uchiyama M, Kim K, Okawa M, Shibui K, Kudo Y, Doi Y, Minowa M, Ogihara R. Sleep loss and daytime sleepiness in the general adult population of Japan. Psychiatry Res. 2000;93(1):1-11.

31. Kamysheva E, Skouteris H, Wertheim EH, Paxton SJ, Milgrom J. A prospective investigation of the relationships among sleep quality, physical symptoms, and depressive symptoms during pregnancy. J Affect Disord. 2010;123(1-3): 317-20

32. Ertmann RK, Nicolaisdottir DR, Kragstrup J, Siersma V, Lutterodt MC, Bech P. Physical discomfort in early pregnancy and postpartum depressive symptoms. Nordic J Psychiatry. 2019;73(3):200-6.

33. Gelaye B, Kajeepeta S, Zhong QY, Borba CP, Rondon MB, Sanchez SE, Henderson DC, Williams MA. Childhood abuse is associated with stressrelated sleep disturbance and poor sleep quality in pregnancy. Sleep Med. 2015:16(10):1274-80.
34. Sanchez SE, Islam S, Zhong QY, Gelaye B, Williams MA. Intimate partner violence is associated with stress-related sleep disturbance and poor sleep quality during early pregnancy. PLoS One. 2016;11(3):e0152199.

35. Yu Y, Li M, Pu L, Wang S, Wu J, Ruan L, Jiang S, Wang Z, Jiang W. Sleep was associated with depression and anxiety status during pregnancy: a prospective longitudinal study. Arch Womens Mental Health. 2017;20(5): 695-701.

36. Lauche R, Hall H, Adams J, Steel A, Broom A, Sibbritt D. Health-care utilisation amongst pregnant women who experience sleeping problems and/or tiredness or fatigue: secondary analysis of a cross-sectional survey of 1835 pregnant women. Sleep Breath. 2016;20(1):355-62.

37. Zhang P, Lou P, Chang G, Chen P, Zhang L, Li T, Qiao C. Combined effects of sleep quality and depression on quality of life in patients with type 2 diabetes. BMC Fam Pract. 2016;17:40.

38. Coventry PA, Hays R, Dickens C, Bundy C, Garrett C, Cherrington A, ChewGraham C. Talking about depression: a qualitative study of barriers to managing depression in people with long term conditions in primary care. BMC Fam Pract. 2011;12:10.

39. Kocsis I, Szilagyi T, Turos J, Bako A, Frigy A. Effect of a gymnastics program on sleep characteristics in pregnant women. Taiwanese J Obstet Gynecol. 2017:56(2):204-9.

40. Baker JH, Rothenberger SD, Kline CE, Okun ML. Exercise during early pregnancy is associated with greater sleep continuity. Behav Sleep Med. 2018;16(5):482-93.

\section{Publisher's Note}

Springer Nature remains neutral with regard to jurisdictional claims in published maps and institutional affiliations.
Ready to submit your research? Choose BMC and benefit from:

- fast, convenient online submission

- thorough peer review by experienced researchers in your field

- rapid publication on acceptance

- support for research data, including large and complex data types

- gold Open Access which fosters wider collaboration and increased citations

- maximum visibility for your research: over $100 \mathrm{M}$ website views per year

At $\mathrm{BMC}$, research is always in progress.

Learn more biomedcentral.com/submissions 